\title{
Parents' Views on Play Based Learning for Children Aged 3-6 Years: Evidence from Selected Early Childhood Education Centres in Zambia
}

\author{
Stella Lungu*, Beatrice Matafwali \\ University of Zambia, Department of Educational Psychology, Sociology and Special Education, Zambia. \\ *Corresponding Author: Stella Lungu, University of Zambia, Department of Educational Psychology, \\ Sociology and Special Education, Zambia.
}

\begin{abstract}
The study explored parents' views on play-based learning for children aged 3-6 years in selected early childhood education centres in Zambia. Qualitative approaches were used to collect data from twentyone participants and the data were analysed thematically. The findings revealed that parents had positive perspectives of play-based learning asserting that play was good for learning, child development, fun and for children's enjoyment. However, most parents were sceptical of how teachers used play to enhance children's intellectual abilities and promote the children's learning of Arithmetic, Reading and Writing. In addition, the study revealed that although parents acknowledged the benefits of play-based learning to children, parents were in support of a more academic oriented path hence they were more inclined to supporting teacherdirected activities that focused on the acquisition of academic knowledge at ECE Centres. Finally, whilst the study revealed that parents liked (prioritized) several aspects about the ECE Centres where their children were enrolled, availability of proper play equipment and play materials were top on the list. Based on the findings, the study recommended that the school administrators and the teachers should initiate orientation seminars on play-based learning for parents to fully comprehend the dynamics of play-based learning.
\end{abstract}

Key words: Early Childhood Education, Home setting, Perception, Play-based Learning.

\section{INTRODUCTION}

Play is important for optimal child development. The acquisition of developmental milestones: language, cognitive, and socioemotional skills is largelyfacilitated through play. Broadly speaking, play involves a range of activities and behaviours (Ginsburg, 2007; Johnson \& Dinger, 2012; MyckWayne, 2010; Nell \& Drew, 2013), encompassing day to day activities such as play on a swing, sliding, building with blocks, dancing to music, reading books, taking turns, singing, rhyming words and pretend play (Matafwali \&Munsaka, 2011; Biddle, Garcia-Navarez\& Henderson, 2013). Play has been defined as a child centred approach and context through which children make meaning of their social worlds through active engagement with objects, people and developmentally appropriate activities (Munsaka\& Matafwali, 2013).Play further involves manipulating of objects including playing with assorted toys which should not just be colourful and attractive but should also be rich in stimulating problem solving skills, reciprocity, cooperation, creativity and basically promote learning and child development (Healey., Mendelsohn., \& AAP Council on Early Childhood, 2019; Milteer., Ginsburg., Council on Communications and Media; Committee on Psychosocial Aspects of Child and Family Health, 2012).Article 31 of the United Nations Convention on the Rights of the Child has recognised play as a human right (United Nations,1989). In the Zambian Early Childhood Education curriculum, play has been identified as a pedagogical strategy aimed at enabling children to have adequate play opportunities to explore their environment as they learn and develop (MESVTEE, 2013). This article explores parents' perspectives on play based learning for children aged 3-6 years in early childhood education centres.

\section{LITERATURE REVIEW}

The socio cultural theory asserts that "play contains in a concentrated form, as in the focus of a magnifying glass, all developmental tendencies" (Vygotsky, 1978:102). Perhaps a significant 
component of the socio-cultural theory is the aspect of "scaffolding" which acknowledges the involvement of a More Knowledgeable Other (MKO) (peer/adult)to guide the children towards the Zone of Proximal Development (ZPD). This entails children playing independently, with just a little indirect guidance from an adult by way of asking questions, giving a hints, or prompt (Bergen, 2008). Thus, significant others in the child's environment including parents, teachers and the children's peers who are more knowledgeable occupy an important place in facilitating children's play. Evidence shows that children's early play experiences in their immediate home settings with parents as primary caregivers remains central in facilitating and initiating play activities in a home setting(Roopnarine 2011; Parmar, Harkness\& Super; 2004). Through play, children develop language and communication skills. It is these oral skills that lay the foundation for development of early literacy skills (Matafwali \& Bus, 2012).

Evidence on parents' perception of play has yielded mixed results. Ali., Chowdhury \&Obaydullah (2019), revealed in their study that although most parents perceived play from a positive point of view, they lacked clear and specific knowledge about the benefits of play in children's development. Despite most parents in this study describing play as meaningful, joyful, happiness, building friendship, entertaining and fun, majority of them were reluctant to allow their children to play because of safety and security reasons. To these parents, ECE centres should not only endeavour to provide more play materials, but also ensure that the play environment is secure and safe for children. in another study that compared perceptions of Jordanian and Syrian refugee parents regarding play in preschool found that Jordanian parents' ratings on the value of play and academic skills were higher than those for Syrian parents (Albatataineh, 2018: 26). Several factors including cultural differences were noted to have been the reason for the variations in their perceptions. The researcher particularly concluded that Syrian parents had limited opportunities to be emotionally attached to their children due to social, political, and the economic circumstances in Syrian refugee camps which might have had an influence on their child rearing and educational practices. However, thestudy revealed that in both the Jordanian and Syrian sample, mothers valued play more than fathers. This attributed to mothers being more involved in playing with their pre-schoolers than fathers who were mostly preoccupied with male dominated activities. Xunyi\& Hui (2018) further explored the constructs of play and found that most parents emphasized play that enhanced children's (pre-) academic skills known as Play for Learning (PL) because the nature of play often focused on academic knowledge achieved through diligence, repetition, and drill practices.O' Gorman \& Ail wood (2012), investigated parents' views on play-based learning in the preparatory year in Australia. The study established that parents held varying definitions of what constitutes play with majority of them linking it to "children's learning, engaging in hands-on activities, and preparation for Year One through a strong focus on academic progress.

In a study by Woolnough (2017) about parents' perceptions of play-based early education, it was found out that although most parents in Nigeria were supportive of the approach to play-based learning, they were sceptical on how the approach worked at operational level. The study emphasised the need for reassurance by educators on provision of necessary resources to support their children's learning and that play-based learning would still have academic components and evidence of learning. Parents wished they could be supported with resources at home to promote and enhance the learning that takes place at school as a way of closing the gap between home and school. A study conducted in Erzurum province of Turkey aimed at exploring parental perceptions and preferences about children between 1 and 5 years old revealed that most of the participants viewed play as a part of child education and a way of supporting development (Babuc, 2015). Although the majority of the parents felt that they did not spend adequate time playing with their children, they were of the view that they were responsible for proper development of their children and for their children's future success in life. The parents believed that play was an essential tool to achieving long term positive outcomes. However, most of the parents felt that in view of the growing expectations from parents, it was somehow difficult to know what ideal parenting involved. Perhaps when it comes to the education of children, education institutions should take it upon themselves to orient parents on their role regarding the support that should be rendered to their children for the parents to know exactly what is required of them regarding their children's education. Parmar. Harkness \& Super (2004) examined the beliefs of Asian and Euro-American parents of preschool-aged children and revealed that Euro-American parents were of the view that play was an important vehicle for early development. On the contrary, 
Asian parents placed emphasis on the importance of an early start in academic training for their children.

Roopnarine (2011) considered variations in parental beliefs about play and participation in play in different cultural communities. The study revealed that parents in western technologically developed societies were more likely to embrace play that supported the children's cognitive and social development and were likely to consider themselves as playmates to children, while parents in more traditional societies often saw play as incidental to childhood development. It was noted that these belief systems were consistent with specific cultural socialization practices and the different developmental goals. In addition, sibling play was more prevalent than mother-child play in some societies. Further, children's play activities were a duplication and a reflection of adult activities and physical settings. Generally, whilst play was perceived as a duplication of culture-specific tasks and behaviours in agricultural and hunting-gathering societies, play served an educational function in technologically developed societies and perhaps in developing countries where the use of technology is slowly becoming the norm in ECE Centres and home settings. Teachers and parents seemed to make use of technology in different ways. For instance, research has shown that in most technological societies children were exposed to gadgets such as Computer/Video games and television sets (programmes) many of which have positive and negative effects on children's development (Allazzam, 2015 \&Subrahmanyam., Kraut., Greenfield., \& Gross, 2000).For example, video gaming is said to be one of the causes of childhood obesity (Bickford, 2010 cited in Allazzam, 2015). In addition, too much exposure to violent video games may contribute to aggressive behaviour in children because children fail to distinguish real life from fiction. Further, children's friendships and family relationships are affected and this may lead to loneliness and depression (Subrahmanyam., Kraut., Greenfield., \& Gross, 2000).Similarly, when children are excessively exposed to children's television programes, research suggests that the exposure could affect children's language and cognitive development, behavioural problems, attention disorder, aggression and obesity (Jusoff, 2009\&Allazzam, 2015).In spite of the many negative effects of video games, Griffiths (2002) suggests that video games are beneficial when they are designed to address a specific problem or to teacha certain skill. Further, other benefits of computer games include; children being able to improve handeye co-ordination, self-esteem, problem-solving skills and spatial abilities (Allazzam, 2015 \& Griffiths, 2002). Samaniego \& Cortes (2007) suggests that television contents which constitute a source of learning through television narratives can teach and enable people to learn values through: the contents themselves, the medium itself and the language.

\section{MeThodology}

A case study design was employed using qualitative approaches. According to Matula, Kyalo, Mulwa\&Gichuhi (2018:69), qualitative research can be applied in order to "understand a social situation from participants' perspective." In this particular study the researchers used qualitative approaches to gain insight and a better understanding of parents' perspectives of play-based learning through collection and analysis of descriptive data.

\subsection{Sample Size}

The sample comprised a total of twenty-one parents who were randomly selected from ECE centres where their children were enrolled. The initial criteria were inclusion of parents whose children were enrolled at ECE centres.

\subsection{Data Collection Instruments}

Focus Group Discussions (FGD) were used to collect detailed information from parents regarding their perspectives of play-based learning at ECE Centres and home settings. As part of triangulation, an Observation Checklist was used by the researcher to establish how play was being implemented at ECE centres.

\subsection{Data Analysis}

Thematic analysis was used to analyse qualitative data. The qualitative data were coded and grouped according to emerging themes.

\section{Results}

This section presents the findings of the study according to the themes under investigation: parents' perspectives of play-based Learning; what they liked at the centres were their children were enrolled; and their perspectives on how they could use play-based learning at home. 


\subsection{Parents' Perspectives of Play-Based Learning.}

Generally, the study revealed positive parental perspectives towards play-based learning asserting that play helps children to develop socially, physically or intellectually; have fun and to enjoy themselves; easily remember new words, how to count and even how to add which is good for the children; make them concentrate and easily understand the lessons; and it makes children enjoy the lessons. Parents particularly observed the following:

Play-based learning is a situation where teachers allow children to play in the classroom and outside the classroom because they want the children to develop socially, physically or intellectually.

Play is good for the children because it helps them to have fun and to enjoy themselves.

Play-based learning is where the lessons are combined with play activities to make the children easily remember what they were learning since children enjoy playing. For example, some pre-school games and rhymes help children to easily remember new words, how to count and even how to add which is good for the children.

Play-based learning is where teachers teach children using play activities to make them concentrate and easily understand the lessons. This is a good strategy because children are difficult to teach. Even at church that is what we do when teaching the children at Sunday school.

Play-based learning is a situation where teachers mix their teaching with play activities to make children enjoy the lessons. A good example is the singing and dancing children do in Pre-schools.

When the parents were probed to give their opinion on whether or not they were satisfied with how their children were learning through play, parents expressed different opinions. The findings revealed that most parents were not satisfied with the way teachers used play to teach children as they expected their children to be engaged in teacher-directed activities that mainly focused on the acquisition of academic knowledge for school readiness. As a result of their dissatisfaction, most parents were sceptical of how teachers used play to enhance children's intellectual abilities and promote the children's learning of numeracy and literacy skills.

The following is what different parents had to say:

I have no doubt that play is good for the children but the manner in which it is used is what is of concern. You know, we take our children to these Centres because we want them to learn new things academically. But if all they do is play minus learning how to read and write, then it is worrying.

I expect my child to have a lot of fun playing on Slides, Swings, Sea-saw and Jumping castle when they go to the Centre but teachers must also make sure that learning is taking place as they teach in class.

Well, the Centre where I take my child, they have a variety of play equipment, toys and plenty of reading materials, but I have observed that all the children do is play instead of them being taught Arithmetic, Reading and Writing. I hear they are expected to learn through play, but I think it is just too much of playing and I wonder if at all learning is taking.

I think teachers should balance teaching and play activities. During lessons, let children learn what will help them academically and during play-time teachers should not just ask children to go and play they need to provide the required play materials for children to have fun and enjoy themselves.

On the contrary, there were a few parents who actually felt that children needed to play more during the early years at ECE Centres and these were their arguments.

My child is in baby class and I sometimes feel that the academic work given to him is too hard for his level. If only he can be allowed to play more, that would be good. 
The other parent had this to say:

You are right, I have noticed that too. I think very young children in Baby class can be allowed to play more because they are still very young.

\subsection{What Parents Liked at the ECE Centres}

On what parents liked at the ECE centres where their children were enrolled, it was revealed that most parents liked the fact that the ECE Centres had proper play equipment and plenty of play materials such as toys; qualified teachers; safety measures at the centre and; and guaranteed transition to grade one after completion of ECE.

Parent A had this to say:

I like the Centre because they have very good play equipment like Swings, climbing monkey bars, Slides, Sea-Saws and materials such as Toys, Building Blocks and Jig-Saw Puzzles and plenty of reading materials.

In addition, Parent $\mathrm{B}$, echoed the same sentiments and had this to say:

I like the fact that the children are given a variety of play materials to play with during play-time. The Centre usually receives assorted play materials from some donors abroad and our children are so privileged to play with beautiful toys.

Furthermore, Parent $\mathrm{C}$ liked the Centre because the Centre had qualified teachers. This is what she said:

I like the Centre because they employ qualified teachers who know how to handle young children very well. My child enjoys being at the Centre because of how he is treated

Parent D liked the fact that the Centre was safe for her child and this is what she said:

I like the safety measures at the Centre. I have a hyper active child who requires attention for him to be safe and I am glad the Centre has mechanisms in place to manage all types of children.

Another key finding was that some parents liked the ECE Centres where their children were enrolled because they did not have to worry about looking for a grade one school place once the child completed ECE considering that grade one school places are sometimes difficult to find. This is what Parent E had to say:

I like this Centre because children who successfully complete their pre-grade are allowed to progress to grade one. This is good because looking for a grade one place is difficult and I don't like the idea of changing schools for my children unless there is a problem.

\subsection{Parents' Perspectives of how to Support Play-Based Learning at Home Settings.}

The study revealed that most parents were of the view that it was important to: encourage children to play educative video games; watch educational cartoons; provide toys for children to play with; create space for children's play at home; play with the children and; allow the children to play with their peers although there was some concern on the sufficiency of play space at some homes. Presented below are narratives from parents on how they can support play based learning:

In my opinion, parents can allow children to play computer or video games for them to develop a creative and innovative mind.

I think we can encourage children to play educative video games and watch educational cartoons like "Dora the Explorer," and "Paw Patrol" since children naturally enjoy watching television.

Well, I think parents should buy plenty of play materials for children to play with. Otherwise, watching television would be the only entertainment for the children.

As parents, we need to play different games with our children to help them develop intellectually and physically. The only problem is that, there is no adequate time to do so 
because you find that by the time you are getting home after work, you are so tired and all you want to do is rest. Even when the child wants to engage you in an activity like playing ball games, you are not keen to participate.

I am also of the view that we need to ensure that we create space for children's play within the home environment but the problem is that some of us have very limited free space at our homes and the yards are equally too small.

When the parents were asked if at all, they take keen interest to know what their children develop and learn from the toys they buy for them, most parents indicated that they bought toys based on their children's interests and gender stereotypes and not necessarily what the children were going to develop and learn.

The following were some of the responses different parents gave:

As for me, it just depends on whether I am buying a toy for my daughter or for my son. For my son, I usually buy toys which most boys like such as toys Cars, Construction toys and different types of Balls. For my daughter, I usually buy different types of Dolls, Teddy Bears, Make-up kits and those packs with cooking utensils.

I buy toys according to what is of interest to my children. Otherwise, when I buy what they do not like they do not express happiness.

Well, not really. Unless I am buying Building blocks, Puzzles and things like that. I try to read what is written on the box to check the content and age appropriateness.

To be honest with you, my children are the ones who suggest the toys I buy for them and I don't take time to know exactly what the children would benefit from the toys I buy.

\section{DISCUSSION}

Similar to the findings by Ali., Chowdhury \&Obaydullah (2019), the study revealed that most parents had positive perspectives of play-based learning asserting that play was good for the children because it helps children to develop and learn, have fun and to enjoy themselves. Further,although some parents lacked clear and specific knowledge about the benefits of play for children's development, parents in this current studyseemedto be knowledgeable of how play benefited the children. Nonetheless, parents were dissatisfied with the choice of play activities teachers engaged their children in at ECE centres. The parents wondered whether or not the play activities that teachers initiated at ECE centres would facilitate acquisition of numeracy, and literacy skills. This finding was similar to that of Woolnough (2017) who reported that parents in Nigeria were sceptical about how the approach of play-based learning worked. The parents reportedly wanted reassurance that teachers would be given necessary resources to support their children's learning and that play-based learning would still have academic components and evidence of learning. The study revealed that although parents in Zambia seemed to acknowledge the benefits of play-based learning to children, most parents were in support of a more academic oriented path hence parents were more inclined to supporting teacher-directed activities that focused on the acquisition of academic knowledge at ECE Centres. This finding was similar to that of Xunyi\& Hui (2018), who postulated that most parents emphasized play that enhanced their children's (pre-) academic skills which often stressed on acquiring academic knowledge achieved through diligence, repetition, and drill practices.

Among various aspects that parents appreciated at the ECE centres where their children were enrolled was availability of appropriate play equipment and play materials such as swings, climbing monkey bars, slides and sea-saws, building blocks and jig-saw puzzles. Other aspects were availability of qualified teachers, safety measures, and transition into grade one. This finding seems to suggest that parents see play materials at ECE Centres as essential not just for fun and enjoyment but for enhancement of child development and children's academic learning. The assertion echoes the findings by Babuc (2015) who proposed that play was an essential tool to achieving long term positive outcomes and that most of the parents viewed play as a part of child education and a way of supporting development.

On how parents support play-based learning within the home setting, most parents indicated that they support play-based learning by encouraging children to play educative computer/video games and 
watch educational cartoons. Arguably, this seems to be a common trend in homes where computers and television sets are readily available considering that computers and television programmes can be an important source of educational information and improvement of hand-eye co-ordination, selfesteem, problem-solving skills and spatial abilities (Allazzam, 2015 \& Griffiths, 2002). In fact, Samaniego \& Cortes (2007) affirm that some television programmes have the potential to facilitate learning of values through the content of the programme, the medium itself and the language.

Additionally, parents supported play-based learning at home settings by providing toys for their children although most of them did not seemingly pay particular attention to know what children benefited from the purchased toys as indicated in the following comment by a parent: "To be honest with you, my children are the ones who suggest the toys I buy for them and I don't take time to know exactly what the children would benefit from the toys I buy".

Research, has shown that parents' knowledge on appropriateness of play materials, safety of the toy, and the skills being promoted (e.g. language skills, social skills, physical skills, problem solving skills, creativity or any other skill) is important in determining the extent to which they will facilitate play- based learning in the home setting (Healey., Mendelsohn., \& AAP Council on Early Childhood, 2019). Thus, school-home collaborations should be enhanced for teachers to support parents in enhancing play at home for continuity of the learning process.

\section{CONCLusion}

In conclusion, the study has clearly demonstrated that parents had a positive perspective on playbased learning pedagogy in ECE centres. The study has further revealed that although parents seemed to acknowledge the benefits of play-based learning to children, parents were in support of a more academic oriented path hence they were more inclined to supporting teacher-directed activities that focused on the acquisition of academic knowledge at ECE Centres. Among the structural aspect of ECE quality, parents liked play equipment and play materials because they stimulated child development and facilitated acquisition of requisite skills such as numeracy and literacy that are necessary for school readiness. In addition, the study revealed that most parents were of the view that play-based learning at home settings could be supported by encouraging children to play educative computer/video games, watch educational cartoons, allow children to play with peers and by parents providing toys for their children to play with. The current study therefore recommends the need to support parents by bridging the knowledge gap as they play an important role in the education of their children hence their perspective have the potential to influence how play is valued and conducted.

\section{SUGGESTIONS}

Based on the findings of the study, the school administrators and the teachers should initiate orientation seminars on play-based learning for parents to be well informed on the dynamics of playbased learning so that they can have a better understanding of the approach. It is hoped that by initiating the orientation seminars, parents will be equipped with sufficient knowledge which would enable them to actively support play-based learning. In addition, there is need for the Ministry of General Education through the Curriculum Development Centre (CDC) to develop a Parent Hand Book on play-based learning linked to the ECE curriculum which could elaborate ECE policies and play-based learning measures which parents can use to support child development and academic learning.

\section{LIMITATIONS}

This was a qualitative study which was not statistically representative hence the major limitation is the fact that the research findings from this study cannot be generalised but can only be interpreted within the context of this current study.

\section{REFERENCES}

[1] Albatataineh.M. (2018). Perceptions of Parents towards Children's Play: a Comparative Study of Perspectives of Jordanians and Syrian Refugees. British Journal of Humanities and Social Sciences. Vol. $19(2)$

[2] Ali. M.S, Chowdhury.K.Q\&Obaydullah. A.K.M. (2019). Parents' Perception towards Play based learning of 3-5 years old children. IJCIRAS | ISSN $(O)$ - 2581-5334| Vol. 1 Issue. 12 
Parents' Views on Play Based Learning for Children Aged 3-6 Years: Evidence from Selected Early Childhood Education Centres in Zambia

[3] Allazzam. M. (2015). The Impact on Children Playing Computer Games. International Journal of Advancements in Research \& Technology, Volume 4, Issue 8, August -2015 15

[4] Babuc, Z. T. (2015). Exploring parental perceptions and preferences about play: A case study in Erzurum. Proceedia - Social and Behavioral Sciences, 197, 2417-2424.

[5] Bergen, D. (2008). Human Development: Traditional and Contemporary theories. Upper Saddle River, NJ: Pearson Prentice Hall.

[6] Biddle G, A. K., Garcia-Navarez. A. \&Henderson, R.J.W. (2013). Early Childhood Education: Becoming a profession. London: Sage Publications.

[7] Curriculum Development Centre. (2014) Language and Literacy: Teacher's Guide 3-4 \&5-6 Years. Lusaka: Curriculum Development Centre.

[8] Ginsberg, K. (2007). The Importance of Play in Promoting Healthy Child Development And Maintaining Strong Parent-Child Bonds. Paediatric. 119 (1) 182 - 191.

[9] Griffiths, M. (2002). The educational benefits of videogames. Education and Health. 20.47-51.

[10] Healey.A., Mendelsohn.A., \&AAP Council on Early Childhood (2019). Selecting Appropriate Toys for Young Children in the Digital Era. Paediatrics. 143(1): e20183348

[11] Johnson, J. A., \& Dinger, D. (2012). Let them play: An early learning (un)curriculum. St. Paul, MN: Redleaf Press.

[12] Jusoff, K. (2009). Television and Media Literacy in Young Children: Issues and Effects in Early Childhood. International Education Studies, 2(3), 151-157.

[13] Lau, G. \& Cheng PuiWah, D. (2010). Learning through Play in the Early Childhood Classroom: Myth or Reality? Hong Kong, Journal of Early Childhood. Vol 9. No 2.

[14] Matafwali, B. \& Bus, A.G. (2013). Lack of familiarity with the language of instruction: A main cause of reading failure by grades 1 and 2 pupils in Zambia. Insights on Learning Disabilities, 10, 31-44.

[15] Matafwali, B. \&Munsaka, E. (2011). An evaluation of community based early childhood programmes in Zambia: A case of four selected districts. Journal of Early Childhood Development, vol. v, 109-131. Nepal: ECD Resource.

[16] Matafwali, B. \&Munsaka, E. (2011) Programmes in Zambia: A case of four selected districts. Journal of Early Childhood Development, vol. v,109-131.

[17] Matula, Kyalo, Mulwa\&Gichuhi. (2018). Academic Research Proposal Writing. Nairobi: Applied Research \& Training Services.

[18] Milteer. R.M., Ginsburg. K.R.; Council on Communications and Media; Committee on Psychosocial Aspects of Child and Family Health. (2012). The importance of play in promoting healthy child development and maintaining strong parent-child bond: focus on children in poverty. Paediatrics. 129(1). Available at: www.pediatrics.org/cgi/content/full/129/1/e204

[19] Ministry of Education, Science, Vocational Training and Early Education (2013). Early Childhood Education Syllabus. Lusaka: Curriculum Development Centre.

[20] Munsaka, E. and Matafwali, B. (2013). Human Development from conception to Adolescence: Atypical Trends. Lusaka: University of Zambia Press.

[21] Myck-Wayne, J. (2010). In defense of play: Beginning the dialog about the power of play. Young Exceptional Children, 13(4), 14-23. doi:10.1177/1096250610376616

[22] O'gorman.L. \&Ailwood, J. (2012). They Get Fed Up with Playing': parents' views on play-based learning in the Preparatory Year. Contemporary Issues in Early Childhood. Volume 13 Number 4, 266-275 www.wwwords.co.uk/CIEC

[23] Nell, M., \& Drew, W. (2013). From play to practice: Connecting teachers play to children's learning. Washington, DC: NAEYC.

[24] Parmar, P., S. Harkness, and C. M. Super. (2004). “Asian and Euro-American Parents' Ethnotheories of Play and Learning: Effects on Preschool Children's Home Routines and School Behaviour." International Journal of Behavioral Development 28 (2): 97-104.

[25] Roopnarine, J. L. (2011). “Cultural Variations in Beliefs about Play, Parent-Child Play, and Children's Play: Meaning for Childhood Development." In The Oxford Handbook of the Development of Play, edited by A. D. Pellegrini, 19-37. Oxford: Oxford University Press.

[26] Samaniego. C. \& Cortes. A. (2007). The Teaching and Learning of Values Through Television. International Review of Education. 53. 5-21. 10.1007/s11159-006-9028-6.

[27] Subrahmanyam, K., Kraut, R., Greenfield, P., \& Gross, E. (2000). The Impact of Home Computer Use on Children's Activities and Development. The Future of Children, 10(2), 123-144. doi:10.2307/16026 92 
[28] United Nations. (1989). Convention on the Rights of the Child. Available online at http://www2.ohchr.org /english/law/crc.htmaccessed on $8^{\text {th }}$ May, 2019.

[29] Vygotsky, (1978). Mind in Society: The development of higher psychological processes. Cambridge, Massachusetts: Harvard University Press.

[30] Woolnough.S. (2017). Parent perceptions of play-based early education in Abuja, Nigeria. Toronto, Ontario: Master of Arts in the Program of Early Childhood Studies. Ryerson University.

[31] Xunyi Lin \& Hui Li (2018) Parents' play beliefs and engagement in young children's play at home, European Early Childhood Education Research Journal, 26:2, 161-176, DOI: 10.1080/1350293 X.2018.144197

\section{AUTHORS' BIOGRAPHY}

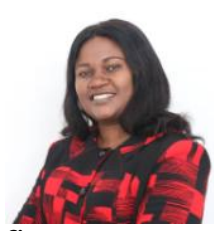

Stella Lungu, is a $\mathrm{PhD}$ student (Sociology of Education) in the Department of Educational Psychology, Sociology, and Special Education at the University of Zambia. She is a holder of a Master of Education in Sociology of Education and a Bachelor of Arts with Education (B.A. Ed) degree from the University of Zambia. Stella has taught and tutored on part-time basis at the University of Zambia for over five years. She has more than six years teaching experience at Secondary School level in the Department of Languages and twelve years of being a Teacher Educator for Early Childhood Education (ECE) teachers. She is passionate about Early Childhood Education studies and sociological issues in education and the society at large.

Beatrice Matafwali, is a Senior Lecturer at the University of Zambia in the Department of Educational Psychology, Sociology and Special Education. She has 15 years of professional experience as a lecturer and researcher in the field of Early Childhood Development, Special Education, and Education studies.

Citation: Stella Lungu, Beatrice Matafwali. "Parents' Views on Play Based Learning for Children Aged 3-6 Years: Evidence from Selected Early Childhood Education Centres in Zambia" International Journal of Humanities Social Sciences and Education (IJHSSE), vol 7, no. 5, 2020, pp. 60-68. doi: http://dx.doi.org/10.20431/2349-0381.0705008.

Copyright: (1) 2020 Authors. This is an open-access article distributed under the terms of the Creative Commons Attribution License, which permits unrestricted use, distribution, and reproduction in any medium, provided the original author and source are credited. 